\title{
Quality of Life Issues in Epilepsy
}

Jane McCagh

Additional information is available at the end of the chapter

http://dx.doi.org/10.5772/58689

\section{Introduction}

There is overwhelming evidence that people with epilepsy (PWE) have a number of psychosocial difficulties which impact greatly on their quality of life [1]. To this end the chapter will summarise some definitive clinical features of the disorder and then go on to provide an overview of the types of psychosocial deficits that PWE experience and the influence of epilepsy related variables on these factors. The chapter will conclude by considering interventions that may alleviate the burden of psychosocial problems.

\subsection{Epilepsy \& psychosocial functioning}

The themes addressed in this chapter emerged from observing the symptoms and behaviours exhibited by patients with epilepsy who were attending a tertiary referral unit in the UK. The majority of patients have intractable epilepsy (difficult to manage seizures) and a number of these patients were being assessed to see if they were viable candidates for surgery. A recurring problem reported by epilepsy patients attending the unit was that they experienced a number of difficulties in relation to social functioning. Such difficulties have been evident in the wider epilepsy population where PWE often report difficulties such as low self-worth, stigma, social isolation, difficulties with interpersonal relationships and in gaining and maintaining employment [1].

In reviewing the literature it is evident that quality of life in PWE is determined by the interplay of a number of multifaceted biopsychosocial factors. Psychosocial factors include comorbid anxiety and depression, cognitive deficits, the impact of stigma, low self-esteem, reduced opportunities for social interaction, difficulties in both intimate and non-intimate relationships and employability [1-15]. The impact of these factors on the quality of life of people with epilepsy in relation to epilepsy related variables will be discussed throughout the chapter. 


\section{Epilepsy}

Epilepsy is the most common serious neurological disorder affecting people across the world with approximately 50 million people living with the condition [16]. The highest incidence and prevalence rates of epilepsy are in the early and later years of life. The largest majority of PWE (approx. 80\%) live in developing countries with limited access to treatment [17]. This can be due to economic constraints but is most commonly a consequence of misconceptions about the origins of epilepsy. Some cultures believe that the condition is not organically based and therefore not treatable by medical intervention. Such misconceptions have been reflected historically where epilepsy was regarded as a 'sacred disease' representing possession by evil spirits or retribution by the gods.

Epilepsy is a complex disorder with many different seizure types and syndromes. An epileptic seizure is defined as 'a transient occurrence of signs and/or symptoms due to abnormal excessive or synchronous neuronal activity in the brain' [19, p 471]. Definitions of epilepsy often focus on the unprovoked and recurrent nature of seizures as not all individuals who experience a seizure will be given a diagnosis of epilepsy. Some individuals have a lower threshold to seizure activity [18]. Single isolated seizures and those which stem from systemic changes in the body, illness or an insult to the head do not constitute a diagnosis [20]. Epilepsy can often be comorbid with or caused by other neurological disorders such as cerebrovascular accidents, brain tumours, brain infection, congenital defects, exposure to toxic agents, degenerative disorders, head injury and birth complications. The aetiology of epilepsy varies in accordance with age.

The remainder of the chapter will go on to discuss how epilepsy related variables interrelate with psychosocial factors and effect quality of life.

\section{Stigma \& misconception}

Historical and media misrepresentations of epilepsy have been overwhelmingly negative and consequently the condition has been clouded by misunderstanding, superstition and discrimination present over many centuries and across different cultures. This in turn increases the experience of stigma in PWE. Contagion beliefs existed up until the $18^{\text {th }}$ century and are still apparent in some African cultures [21-23]. Laws prohibiting marriage in both the UK (until 1970) and America (1956) have only been revoked in the past sixty years [23-24] and more recently over a third of PWE were refused one or more types of insurance in the UK [25]. Cross culturally the impact of stigma on PWE has caused them to be excluded from important social roles, under achieve in school, to find it more difficult to gain employment, have intimate relationships or maintain family relations [1, 21, 26-28]. Consequently negative attitudes and lack of family support render the individual as being more vulnerable to psychosocial difficulties [2]. Conversely recent research suggests that attitudes towards PWE have become more positive [29-31]. 
Misconception, myths and stereotypes are still prevalent in media portrayals of epilepsy despite advances in education [32]. These misconceptions contribute to the psychosocial limitations and stigma experienced by PWE. The idea that epilepsy is defined by the symptoms of a tonic clonic seizure is often perpetuated by the media. Media portrayals are often misguided by ancient myths that see the person with epilepsy as being possessed by demons, frothing at the mouth, violent and in need of urgent medical care [32-33]. Consequently the media can hinder educating people about epilepsy by broadcasting inaccurate portrayals or misinformation [23]. Research suggests that misconceptions are more evident in individuals who do not know someone with epilepsy [32].

Negative attitudes in society have created fear and stigma. The stigma of epilepsy can often be more debilitating for PWE than presenting symptoms. Subsequently individuals with epilepsy conceal their condition or are isolated within their family in an attempt to lessen the social stigma associated with the disorder and to increase marital prospects [2,12]. Psychosocial limitations in relation to employment and relationships are more likely to be a consequence of stigma in society than symptoms of epilepsy [23]. Withdrawing from society in order to reduce the experience of stigma can greatly impact on the quality of life of PWE by making them feel more socially isolated, have less social opportunities and smaller social support networks. This in turn can reduce their ability to cope with epilepsy. The uncertainty of having a seizure in public without warning can increase the likelihood of withdrawal. This is supported by research findings where fear of having a seizure and the uncertainty associated with epilepsy (such as if seizures will ever be controlled) were primary concerns of individuals living with the condition [7]. This uncertainty can increase vulnerability in social situations and greatly impact on quality of life $[1,34]$.

The presence of stigma is complex and researchers have established two different types of stigma affecting PWE. Enacted stigma is when PWE experience discrimination because of their condition and felt stigma is apparent when PWE fear being subjected to enacted stigma [35]. Often there is a difference between the two, with felt stigma being more prevalent [36-37]. In a large cross cultural study of with over 5,000 participants, 51\% of PWE felt stigma as a consequence of having the condition [3]. Perceived stigma is subjective and will differ across individuals. Felt stigma has been shown to depend on whether the individual feels that they have been discriminated against in the work place or constrained in their day to day life as a consequence of having epilepsy [38]. Personality, coping ability and the perceived impact of epilepsy in gaining and maintaining employment can greatly influence felt stigma [39] and increased time spent in education has been shown to reduce felt stigma [38]. The severity of the condition in early life has been found to impact on psychosocial sequalae and treatment interventions at this stage can be effective in reducing felt stigma [12,40].

Felt and enacted stigma are influential in getting work and keeping it and stigma has far reaching consequences that impact upon interpersonal relationships, employability, health and quality of life [12; 41]. Children may feel stigma because they are subjected to an overprotective parental style which in turn may compromise their self-esteem when they are older [42-44]. 
Particular clinical features of epilepsy can influence feelings of stigma and psychosocial functioning. Severe and frequent seizures, a chronic form of epilepsy and comorbidity of other conditions can increase psychosocial risk [2]. Becoming seizure free has been reported as the most important epilepsy related factor in relation to quality of life [45]. Seizure type, frequency, severity, age of onset and duration of epilepsy can greatly impact on stigma. PWE who experience more frequent seizures or whose seizures are not well controlled report more stigma, and tonic clonic seizures are more likely to induce stigma due to their dramatic nature and the attention they draw to the individual $[3,9]$.

\section{Psychological factors: Anxiety and depression}

Both anxiety and depression are common comorbid features in PWE yet psychopathology is undertreated and underdiagnosed [17]. Forty to sixty percent of PWE display symptoms of depression and more than $40 \%$ present with anxiety $[8,46]$. Depression is 4 to 5 times more likely in PWE than in the general population [16] and anxiety is the most common form of psychopathology reported [4, 9]. Suicide is also far more common in PWE than in the general population [47-48]. There is a reciprocal relationship between anxiety, depression and epilepsy such that those with anxiety and depression are more likely to experience epilepsy and those with epilepsy are more likely to experience anxiety and depression [46, 49-51]. The exact mechanism that underpins this relationship as yet is not fully understood.

Depression and seizure worry were found to be the most influential predictors of quality of life in people with intractable epilepsy [56]. Surgery has been shown to significantly reduce anxiety and increase quality of life in patients who have become seizure free [57]. Seizure related variables such as age of onset, seizure type, frequency, severity, duration, side effects of AED's, underlying aetiology and difficult to control seizures all impact on the prevalence of depression and anxiety [9, 11, 58-61].

Seizure activity in itself can be anxiety inducing especially if medial temporal lobe structures such as the amygdala are involved. Anxiety can occur before, during and after a seizure [46]. PWE may fear having a seizure which will in turn raise anxiety thresholds as will the associated stigma of having a seizure in public [7]. To this end PWE can often isolate themselves so as not to have a seizure at an inopportune moment [62]. Consequently social isolation is very common in PWE [2]. Increased feelings of anxiety and depression can be further compounded by reduced social opportunities, lack of social support, poor self-esteem, a reduced sense of mastery, stigma and discrimination, an overprotective parental style in childhood or vocational disability [35, 52-54, 63-70]. Self-esteem and sense of mastery have been inversely related to higher scores on measures of depression and anxiety in PWE [71].

\section{Dispositional factors: Self-esteem and sense of mastery}

Unpredictability is central to living with epilepsy. Individuals may not know when a seizure will occur and often have difficulty accepting living with a chronic condition that may or 
may not improve. This can cause PWE to feel that they lack control over their life, can lower mood and heighten feelings of anxiety [6, 52-54]. This has been reflected in research where PWE demonstrate a lower sense of mastery in relation to healthy controls [55].

Seizure severity and frequency have been shown to be the most influential factors in determining self-esteem and sense of mastery in PWE [61, 72]. Knowledge has been found to mediate the impact on self-esteem. Adolescents with more awareness of their condition report higher levels of self-esteem and educational interventions aimed at increasing knowledge have been successful at enhancing self-esteem in PWE [72-73].

Low self-esteem is commonly reported in PWE and is often mediated by employability, with those being unemployed reporting poorer self-esteem [4, 7, 9, 39, 74-76]. Research suggests that PWE with an increased sense of mastery are less likely to be affected by stigma and more likely to adhere to drug therapy [77]. Over protective parental styles can work to reduce a sense of mastery and consequently make PWE less independent in adulthood [43].

\section{Social factors: Social isolation and relationships}

Epilepsy has been shown to reduce opportunities for social interaction and PWE can isolate themselves for fear of having a seizure in public and the injury this may cause [7, 10]. Parents may have been over protective in early life which has impeded important independent living skills and confidence in social settings $[2,78]$. PWE may also find it harder to gain employment and so are not afforded the same social networks as people without the condition. A reduction in social life has many confounding consequences in terms of social support. Social support can be a protective factor in aiding PWE to cope with living with a chronic condition. The opportunity to develop relationships and maintain them can be compromised and this is evident in the reduced marital status and likelihood of parenting a child in PWE $[4,7,62$, 79-81]. Seizure frequency and age of onset have been negatively related to marital status with those who have more frequent seizures and being younger at the age of onset being less likely to marry [9].

A research study investigated the employment, marital, social and educational status of 343 PWE [81]. The marital status of males and females over the age of twenty was much lower than that of the general population (males 33\% compared to $65 \%$ and females $46 \%$ compared to $73 \%$ ). Poor seizure control was indicative of people with poor social status. A similar disparity was found in another study where $42 \%$ of PWE in comparison to $71 \%$ without epilepsy were married [4].

Parental beliefs may be self-fulfilling, one study found that parents who believe their child will experience stigma and experience limitations reported more behavioural problems in their children than parents who did not hold such beliefs 82]. This study also found that children who report their parents as over controlling had more behavioural problems than children with epilepsy who did not. The authors concluded that seizure type and frequency did not predict behavioural problems but parents perceived stigma, perceived limitations and extent of control did. 
Young people with epilepsy report social isolation as the most influential factor in determining their quality of life and find it especially difficult to take part in social activities outside of their home environment and to make friends [62]. PWE find it very hard to develop friendships [2], perceived and enacted stigma, lower self-esteem, lack of employment and reduced social opportunities may well account for this.

Epilepsy can have consequences for the whole family. There is an increased likelihood of mental health problems, stress, reduced social opportunities, marital problems and lower selfesteem in families of PWE [83]. Parental anxiety can also reduce quality of life in children with epilepsy and carers of PWE report being discontent due to reduced social and personal opportunities as a consequence of their role [84-85].

\section{Education \& employment}

Children with epilepsy have been shown to underachieve at school in comparison to their peers and are more prone to educational difficulties [7, 34, 62]. These difficulties may arise as a consequence of a number of factors. Drug therapy and post ictal confusion may slow cognitive functioning and impact on children's capacity to learn. Children who experience absence seizures in class can often be mistaken for daydreaming, consequently they may not take in all the material taught to them or their attentiveness and behaviour in class may be misinterpreted by the teacher and result in adverse consequences. Children with more severe seizure types may miss time off school and may also be more prone to stigma if they have a seizure in class. Seizures can impair storage of learned information and consequently frequent seizures are more likely to interfere with educational progress [22].

PWE and those who have a history of epilepsy are prohibited by law from a variety of occupations [86]. Practices that discriminate against people with epilepsy are another major contributing factor to unemployment. Worldwide PWE are unemployed and underemployed in relation to the general population [23, 87]. Seizure related variables contribute to this, PWE who experience frequent seizures have less chance of employment and so do those who experience tonic clonic seizures [9, 88-89]. Adequate seizure control, early age of onset, stigma, side effects of AEDs, poor self-efficacy, poor social skills, education level, social isolation, cognitive deficits, negative attitudes of family members, employers and teachers have all been linked to unemployment and underemployment [90-95].

Internal work beliefs have been highlighted as an important factor in the successful inclusion of people with epilepsy into the workplace [91]. Self-worth, worry about safety at work, perceptions of the likelihood of injury in relation to self and others at work and attitudes of family members were primary factors in work status. A major barrier is stigma which in turn may lower self-worth and discourage PWE from seeking employment, conversely being part of the workforce is also likely to increase self-worth [62, 75 \& 91]. As well as individual feelings of stigma, professional stigma may affect employability in the work place [97]. Perceptions of stigma in the workplace and experience of stigma have been found to be of a similar magnitude $[40,98]$. Discrimination is apparent in relation to the availability of employment and employers 
who recruit PWE and in those who lose their jobs after diagnosis $[44,96]$. Whilst the PWE may worry about being discriminated against in the workplace, employers also hold negative attitudes about employing PWE [97-98].

The IBE Employment Commission [cited in 77] conducted a cross cultural study investigating factors that contributed to unemployment. PWE attributed their employment difficulties to; employers having stigmatised views, lack of self-worth, missing school and training, the uncertainty of whether epilepsy will cause a problem in the workplace and not getting the job they want. They felt that laws against discrimination, vocational assessment and epilepsy associations working together with employers would help solve the problem [77].

\section{Strategies to enhance quality of life}

Clearly improvements in diagnostic procedures and medical intervention will have important consequences for management, prognosis and psychosocial outcome of epilepsy and in turn improve quality of life. For example, seizure severity is the most influential clinical feature that impacts on felt stigma so seizure management is fundamental in reducing psychosocial consequences in relation to stigma. Two main avenues to increase quality of life in PWE are promoting attitude change in society and in the individual.

Many of the psychosocial difficulties experienced by people with epilepsy stem from the society within which the individual lives which can determine how restricted they are as a consequence of their condition. Misconception about epilepsy is still prevalent in today's society and is influenced by inaccurate perceptions of the disorder. Such representations of epilepsy are disseminated by the media who perpetuate myths and stereotypes that consequently maintain stigma. Cultural differences in how epilepsy is perceived can influence whether PWE receive adequate treatment, the only way to resolve this is to educate society to increase understanding and reduce stigma.

Felt stigma is reported to be the main obstacle for the individual with epilepsy and impacts greatly on social networks, relationships and employability. PWE who have developed efficient coping techniques, have high self-worth and foster more positive attitudes towards their condition are at less risk of psychosocial dysfunction [41, 99-103]. Therefore interventions that focus on increasing self-worth, developing effective coping strategies and positive cognition will help the individual accept their diagnosis, reduce psychosocial deficits and ultimately enhance quality of life. Cognitive behavioural therapy is likely to be particularly useful to this end and is also effective in managing the comorbid impact of anxiety and depression which are common in PWE.

Interventions that educate and integrate PWE more into society and increase social opportunity would reduce feelings of isolation and enhance coping strategies. Education both in schools and the wider community will help reduce stigma which in turn will enhance social prospects. The impact of education is apparent in adolescents with more knowledge about their condition who report higher levels of self-esteem [73]. Social anxiety has been related to 
knowledge of the condition such that PWE who have more knowledge are less likely to feel socially anxious [73]. Individual and family counselling may also work to enhance self-esteem in PWE [12].

Support groups for both the individual and their family can increase social support and facilitate coping strategies [104-105]. Educating families and PWE will enable better selfmanagement of the condition and reduce seizure activity which may be effective in reducing psychosocial sequalae and felt stigma. Non adherence to medication has been found to be the main reason for a seizure on PWE, also lack of awareness of the condition can increase felt stigma in PWE [106]. Stress also plays a significant role in seizure activity so stress management techniques may prove to be useful in aiding PWE to reduce seizure triggers.

Respite, social support groups and increased education for families of children with epilepsy would be useful in highlighting how parental behaviour can impact on the child [85]. This would help reduce the impact that parental anxiety and overprotectiveness can have on the self-esteem, independence and overall quality of life of the child now and in later life.

Vocational interventions could increase employability and confidence in dealing with epilepsy related issues in the work place especially in relation to disclosure of the disorder and how best to manage this. PWE report being very concerned and unsure about disclosing their condition when applying for jobs [107]. Role play may be useful in helping to increase the confidence of PWE in being able to disclose their condition and aid them in explaining to employers and colleagues what they should do in the event of a seizure [108]. This may have another added benefit by increasing feelings of control and sense of mastery in PWE and by encouraging positive coping strategies. Another strategy to improve employability is to make vocational training more available to PWE [97].

\section{Chapter summary}

This chapter has reviewed the main psychosocial difficulties PWE experience as consequence of epilepsy and its treatment. The main psychosocial issues stem from felt and enacted stigma which can reduce social opportunities in a number of ways. Stigma impacts on self-esteem, sense of control, the ability to gain and sustain employment, to form and maintain relationships and can increase feelings of social isolation. PWE may have a reduced sense of autonomy as a consequence of being exposed to over protective parental styles and underachieve in the education system due to ill health and absence. PWE are more commonly unemployed or underemployed than the general population which may well be a consequence of stigma or disruptions to academic engagement. This in turn can increase feelings of isolation which may also be compounded by the fear of having a seizure in public. Reduced autonomy and social opportunity can impact on building friendships and relationships which is evident in the reduced marital status of PWE in relation to the general public.

Psychiatric comorbidities such as anxiety and depression are often present in PWE, these can precede and be an outcome of having the condition and impinge on psychosocial outcomes. 
Psychosocial factors are influenced by a number of clinical features of epilepsy such as seizure frequency, type and severity, duration of the condition, age of onset, aetiology and comorbid conditions. Seizure activity can impair cognitive dysfunction as can AED therapy. Memory deficits are the most commonly reported deficit and seizure activity can disrupt memory consolidation, learning and information storage which can interfere with academic progress consequently PWE may underachieve in education which in itself can reduce psychosocial opportunities, employability and financial status.

It is worth noting that many of the psychosocial difficulties discussed are pertinent to individuals with intractable epilepsy where much of the research has been conducted as the severity of the disorder has more profound effects on psychosocial functioning so may not be relevant to all PWE [2].

\section{Author details}

Jane McCagh*

Liverpool Hope University, England

\section{References}

[1] McCagh J., Fisk J.E., Baker G.A. Epilepsy, psychosocial and cognitive functioning. Epilepsy Research, 2009; 86 1-14.

[2] Austin K. and deBoer H. Disruptions in social functioning and services facilitating adjustment for the child and adult. In: Engel Jr. J., Pedley, T.A. (eds.) Epilepsy: A Comprehensive Textbook). Philadelphia: Lippincott-Raven; 1997 p2191-2201.

[3] Baker G A., Brooks J., Buck D., Jacoby A. The stigma of epilepsy: a European perspective. Epilepsia 2000; 41 98-104.

[4] Collings J. A. Psychosocial well-being and epilepsy: an empirical study. Epilepsia $1990 ; 31,418-426$.

[5] Corcoran R., Thompson P. Epilepsy and poor memory. Who complains and what do they mean? British Journal of Clinical Psychology 1993; 32 199-208.

[6] de Souza.E.A.P. and Salgado P.C.B. A psychosocial view of anxiety and depression in epilepsy. Epilepsy \&Behavior 2006; 8 232-8.

[7] Fisher R.S., Vickrey B.G., Gibson P., Hermann B., Penovich P., Scherer A. et al. The impact of epilepsy from the patient's perspective II: Views about therapy and health care. Epilepsy Research 2000; 41 53-61. 
[8] Grabowska-Grzyb A., Jędrzejczak J., Nagańska E., Fiszer U. Risk factors for depression in patienst with epilepsy. Epilepsy \&Behavior 2006; 8 411-417.

[9] Jacoby A., Baker G.A., Steen N., Potts P., Chadwick D.W. The clinical course of epilepsy and its psychosocial correlates: findings from a U.K. community study. Epilepsia 1996; 37 148-61.

[10] Mittan R.J. Fear of Seizures. In: Whitman S. and Hermann B. (eds.). Psychopathology in Epilepsy: Social Dimensions. Oxford: Oxford University Press; 1986.

[11] Mensah S.A., Beavis J.M., Thapar A.K., Kerr M.P. A community study of the presence of anxiety order in people with epilepsy. Epilepsy \&Behavior 2007; 7 438-46.

[12] Morrell M.J. Stigma and epilepsy. Epilepsy \& Behaviour, 2002; 3 S21-5.

[13] Scicutella A.B., Ettinger A. Treatment of anxiety in epilepsy. Epilepsy \&Behavior $2002 ; 3$ (5S) 10-12.

[14] Suurmeijer T.P., Reuvekamp M.F, Aldenkamp B.P. Social functioning, psychological functioning and quality of life in epilepsy. Epilepsia 2001; $421160-8$.

[15] Thompson P.J. and Corcoran R. Everyday memory failures in people with epilepsy. Epilepsia 1992; 33 (suppl.6.) S18-S20.

[16] Brodie M.J. and Schachter S.C. Epilepsy, (2nd ed.). Oxford: Health Press; 2001.

[17] de Boer H.M., Mula M., Sander J.W. The global burden and stigma of epilepsy. Epilepsy \&Behavior 2008; 12 540-546.

[18] McCagh J. Epilepsy: classification, aetiology and management. In R. E. D., Bautista (ed.), Epilepsy: A century of discovery. New York: Nova Science Publishers; 2012 p31-40.

[19] Fisher R.S., van Emde Boas W., Blume W., Elger C., Genton P., Lee P., Engel Jr J. Epileptic seizures and epilepsy: definitions proposed by the International League Against Epilepsy (ILAE) and the International Bureau for Epilepsy (IBE). Epilepsia 2005; 46 470-471.

[20] Baker G.A. and Jacoby A. (Eds.). Quality of life in epilepsy beyond seizure counts in assessment and treatment. Amsterdam: Harwood Academic Publishers 2000.

[21] Carod-Artal F.J., Vazquez-Cabrera C.B. An anthropological study about epilepsy in native tribes from Central and South America. Epilepsia 2007; 48 886-893.

[22] deBoer H.M. Epilepsy and society. Epilepsia 1995; 36 S8-11.

[23] International League Against Epilepsy. The history and stigma of epilepsy. Epilepsia, 2003; 44 (suppl. 6): 12-14.

[24] Epilepsy Foundation of America. The legal rights of persons with epilepsy, (6 ${ }^{\text {th }}$ ed). Landover: MD; 1992. 
[25] Jacoby K., and Jacoby A. Epilepsy and insurance in the UK: an exploratory survey of the experiences of people with epilepsy. Epilepsy \& Behavior2005; 5 884-94.

[26] McCagh J. Epilepsy, myths, stereotypes \& stigma. Brain Research Journal 2010; 3 75-88.

[27] ILAE/IBE/WHO. "Out of the shadows": global campaign against epilepsy. Annual Report. Geneva: WHO; 1999.

[28] Wiebe S., Bellhouse D.R., Fallahay C., Eliasziw M. Burden of epilepsy: the Ontario Health Survey. Canadian Journal of Neurological Science 1999; 26 263-70.

[29] Jacoby A., Gorry J., Gamble C., Baker G.A. Public knowledge, private grief: a study of public attitudes to epilepsy in the United Kingdom and implications for stigma. Epilepsia 2004; 45 1405-15.

[30] Jacoby A., Gorry J., Baker G.A. Employers' attitudes to employment of people with epilepsy: still the same old story? Epilepsia 2005; 46 1978-1987.

[31] Jacoby A., Snape D., Baker G.A. Epilepsy and social identity: the stigma of a chronic neurological disorder. Lancet Neurology 2005; 4 171-8.

[32] Baxendale S. and O'Toole A. Epilepsy myths: alive and foaming in the 21st century. Epilepsy and Behavior 2007; 11 192-196.

[33] Krauss G.L., Gondek S., Krumholz A., Paul S., Shen F.“'The scarlet E”: the presentation of epilepsy in the English-language print media. Neurology 2000; 54 1894-8.

[34] International League Against Epilepsy. Living with epilepsy: Employment. Epilepsia 2003; 44, (suppl. 6): 49-50.

[35] Scambler G. Sociological aspects of epilepsy. In: Hopkins A. (ed.) Epilepsy. New York: Demos; 1987 p 497-510.

[36] International League Against Epilepsy. Living with epilepsy: Epilepsy education within statutory school system. Epilepsia 2003; 44 (suppl. 6): 45-48.

[37] Jacoby A. Felt versus enacted stigma: a concept revisited. Evidence from a study of people with epilepsy in remission. Social Science Medicine 1994; 38 269-74.

[38] Ryan R., Kempner K., Emlen A.C. The stigma of epilepsy as a self concept. Epilepsia 1980; 21 433-44.

[39] Lee S. What we confront with employment of people with epilepsy in Korea. Epilepsia 2005; 46 57-8.

[40] Chaplin J.E., Yepez Lasso R., Shorvon S.D. and Floyd M. National general practice study of epilepsy: the social and psychological effects of a recent diagnosis of epilepsy. British Medical Journal 1992; 304 1416-1418. 
[41] Smeets V.M.J., van Lierop B.A.G., Vanhoutvin J,P.G., Aldenkamp A.P., Nijhuis F.J.N. Epilepsy and employment: Literature review. Epilepsy \&Behavior 2007; 10, 354-362.

[42] Goodyer I. The influence of epilepsy on family functioning. In: Hoare P. (ed.). Epilepsy and the Family: A Medical Symposium on New Approaches to Family Care. Manchester: Sanofi UK Ltd; 1998.

[43] McCollum A.T. The chronically ill child: A guide for parents and professionals. New Haven, CT: Yale University Press; 1981.

[44] Scambler G. and Hopkins A. Social class, epileptic activity and disadvantage at work. Journal of Epidemiology and Community Health 1980; 34 129-33.

[45] Jacoby A. Epilepsy and the quality of everyday life: findings from a study of people with well controlled epilepsy. Social Science \& Medicine 1992; 43 657-666.

[46] Munger Clary M. Anxiety and epilepsy: what neurologists and epileptologists should know. Current Neurology \& Neuroscience Reports, 2014; 14445.

[47] Pompili M., Girardi P., Tatarelli R. Death from suicide versus mortality from epilepsy in the epilepsies: A meta-analysis. Epilepsy \& Behaviour 2006; 9 641-8.

[48] Pompili M., Girardi P., Ruberto A., Tatarelli R. Suicide in the epilepsies: a meta-analytic investigation of 29 cohorts. Epilepsy \&Behavior 2005; 7 305-10.

[49] Hesdorffer D.C., Hauser W.A., Annergers J.F., Cascino G. Major depression is a risk factor for seizures in older adults. Annals of Neurology 2006; 47 246-249.

[50] Forsgren L. and Nystrom L. An incident case referent study of epileptic seizures in adults. Epilepsy Research 1999; 6 66-81.

[51] Hesdorffer D.C., Hauser W.A., Olafsson E., Ludvigsson P., Kjartansson O. Depression and suicide attempt as risk factors for incident unprovoked seizures. Annals of Neurology 2006; 59 35-41.

[52] Brier J.I., Fuchs K.L., Brookshire B.L. Quality of life perception in patients with intractable epilepsy or pseudoseizures. Archives of Neurology 1998; 55 660-5.

[53] Salgado P.C.B. and Souza E.A.P. Qualidade de vida em epilepsia e percepcao de controle de crises. Arq Neuropsiquiatria 2001; 19 537-40.

[54] Vasquez B. and Devinsky O. Epilepsy and anxiety. Epilepsy \&Behavior 2003; 9 S205 .

[55] De Vellis R.F., De Vellis B.M., Wallston B.S., Wallston K.A. Epilepsy and learned helplessness. Basic and Applied Social Psychology 1989; 1 241-253.

[56] Loring D.W., Meador K.J., Lee G.P. Determinants of quality of life in epilepsy. Epilepsy \&Behavior 2004; 5 976-980. 
[57] Taft C., Sager Magnusson E., Ekstedt G., Malmgren K. Health-related quality of life, mood, and patient satisfaction after epilepsy surgery in Sweden-A prospective controlled observational study. Epilepsia 2014 (in press) 1-8.

[58] Kanner A.M. and Balabanov A. Depression and epilepsy: how closely related are they? Neurology 2002; 58 S27-39.

[59] Mendez, M.F., Cummings, J.L., Benson, D.F. Depression in epilepsy: Significance and phenomenology. Archives of Neurology 1986; 43 766-70.

[60] Smith D.F., Baker G.A., Dewey M. Jacoby, A and Chadwick D.W. Seizure frequency, patient perceived seizure severity and the psychosocial consequences of intractable epilepsy. Epilepsy Research 1991; 9 231-241.

[61] Thompson P.J. Psychosocial aspects of epilepsy. In: Duncan J.S., Sisodiya S.J.J., Smalls J.E. (eds.). Epilepsy 2000 from science to patient. I.L.A.E.; 2000.

[62] Chaplin J.E., Yepez R., Shorvon S.D. Floyd M. A quantitative approach to measuring the social effects of epilepsy. Neuroepidemiology 1990; 9 151-8.

[63] Dell J. Social dimensions of epilepsy: stigma and response: In Whitman S. and Hermann B. Psychopathology in epilepsy: social dimensions. New York: Oxford University Press; 1986.

[64] Ferrari M., Matthews W.S., and Barabas G. The family and child with epilepsy. Family Process 1983; 22 53-59.

[65] Hecimovic H., Goldstein J.D., Sheline Y.I., Gilliam F.G. Mechanisms of depression epilepsy from a clinical perspective. Epilepsy Behaviour 2003; 4 (suppl. 3.) S25-30.

[66] Hermann B.P. and Wyler A.R. Depression, locus of control, and the effects of epilepsy surgery. Epilepsia 1989; 30 332-8.

[67] Jacoby A. Felt versus enacted stigma: a concept revisited. Evidence from a study of people with epilepsy in remission. Social Science Medicine 1994; 38 269-74.

[68] Mungas D. Interictal behaviour abnormality in temporal lobe epilepsy. Archives of General Psychiatry, 1982; 39 108-11.

[69] Baker G A. The psychosocial burden of epilepsy. Epilepsia 2002; 43 (suppl.6.) 26-30.

[70] Baker G.A., Smith D.F., Dewey M., Jacoby A., Chadwick D.W. The initial development of a health-related quality of life model as an outcome measure in epilepsy. Epilepsy Research, 1933; 16 65-81.

[71] Baker G.A., Spector S., McGrath Y., Soteriou, H. Impact of epilepsy in adolescence: A UK controlled study. Epilepsy \&Behavior 2005; 6 556-62.

[72] Snead K., Ackerson J., Bailey K., Schmitt M.M., Madan-Swain A., Martin R.C. Taking charge of epilepsy : the development of a structured psychoeducational group inter- 
vention for adolescents with epilepsy and their parents. Epilepsy \&Behavior 2004; 5 $547-56$

[73] Jahoda M. Employment and unemployment: a social psychological analysis. Cambridge: Cambridge University Press; 1982.

[74] Levin R., Banks S., Berg B. Psychosocial dimensions of epilepsy: a review of the literature. Epilepsia 1988; 29 805-16.

[75] Chaplin J. Vocational assessment and intervention for people with epilepsy. Epilepsia 2005; 46 S1 55-6.

[76] Schachter S.C.Improving quality of life beyond seizure control. Epileptic Disorders 2005; 7 (suppl. 1.), S34-S38.

[77] Lothman D.J., Pianta R.C., Clarson S.M. Mother-child interaction in children with epilepsy: relations with child competence. Journal of Epilepsy, 1990;3 157-163.

[78] Arnston P., Drodge D., Norton R. and Murray E. The perceived psychosocial consequences of having epilepsy. In: Whitman S. and Hermann B.P. (eds.) Psychopathology in epilepsy: social dimensions. New York: Oxford University Press; 1986.

[79] Zahn C.A., Morrell M.J., Collins S.D., Labiner D.M., Yerby M.S. Management issues for women with epilepsy: a review of the literature. American Academy of Neurology Practice Guidelines. Neurology 1998; 51 949-56.

[80] Callaghan N., Crowley M., Goggin T. Epilepsy and employment, marital, education and social status. Irish Medical Journal 1992; 85 17-19.

[81] Carlton-Ford S., Miller R., Mealeigh N., Sanchez N. The effects of perceived stigma and psychological over-control on the behavioural problems of children with epilepsy. Seizure 1997; 6 383-391.

[82] Ellis N., Upton D., Thompson P. Epilepsy and the family: A review of current literature. Seizure 2000; 9 22-30.

[83] Thompson P.J. and Upton D. The impact of chronic epilepsy on the family. Seizure 1992; 1 (1) 43-48.

[84] Williams J., Steel C., Sharp G.B. Parental anxiety and quality of life in children with epilepsy. Epilepsy \&Behavior 2003; 4 (5) 483-6.

[85] Jacoby A. and Baker G.A. Psychosocial handicaps associated with the epilepsies. In: Vinken P.J. and Bruyn G.W. (eds.). Handbook of Clinical Neurology. Amsterdam, Elsevier Press; 2000.

[86] Chaplin J.E., Wester A., Tomson T. Factors associated with the employment problems of people with established epilepsy. Seizure 1998; 7 299-303.

[87] International League Against Epilepsy. Pharmacological treatment. Epilepsia 2003; 44 (suppl 6): 33-34. 
[88] Yagi K. Epilepsy: comprehensive care, quality of life, and factors preventing people with epilepsy from being employed. Clinical Therapy, 1998;20 (suppl. A) A19-29.

[89] Rätsepp M., Õun A., Haldre S., Kaasik A. Felt stigma and impact of epilepsy on employment status among Estonian people: exploratory study. Seizure 2000; 9 391-401.

[90] Bishop M. Determinants of employment status among a community-based sample of people with epilepsy: implications for rehabilitation interventions. Rehabilitation Counseling Bulletin 2004; 47 112-120.

[91] Clarke B.B., Upton A.R.M., Castellanos C. Work beliefs and works status in epilepsy. Epilepsy \& Behavior 2006; 119-125.

[92] Devinsky O. Vickery B., Hays R., Perinne K., Hermann B., Meador K et al. Quality of life in epilepsy:QOLIFE-89 instrument development. Neurology 1994; 44 (suppl.2) A141.

[93] Seidenberg M., and Clemmons D.C. Maximising school functioning and the schoolto-work transition. In: Engel, J. Jr., Pedley. T.A. (Eds.). Epilepsy: a comprehensive textbook. Philadelphia: Lippincott-Raven; 1988 p2203-2209.

[94] Thorbecke R., and Fraser R.T. The range of needs and services in vocational rehabilitation. . In: Engel J. Jr., Pedley T.A. (eds.). Epilepsy: a comprehensive textbook Philadelphia: Lippincott-Raven; 1997 p2211-2226.

[95] International League Against Epilepsy. Epidemiology. Epilepsia 2003; 44 (suppl. 6): 17-18.

[96] Thompson P.J. and Oxley J. Socioeconomic accompaniments of severe epilepsy. Epilepsia 1988; 29 (suppl.1.) : S9-18.

[97] Hauser W.A. and Hesdorffer D.C. Epilepsy: frequency, causes and consequences. New York: Landover, MD, Epilepsy Foundation of America; 1990.

[98] Bautista R.E.D. and Wludyka P. Factors associated with employment in epilepsy patients. Epilepsy \& Behavior 2005; 10 89-95.

[99] Cooper M. Epilepsy and employment: employer's attitudes. Seizure 1995; 4 193-9.

[100] Oosterhuis A. Coping with epilepsy: the effects of coping styles on self-perceived seizure severity and psychological complaints. Seizure 1999; 8 93-6.

[101] Livneh H., Wilson L.M., Duchesneau A., Antonak R.F. Psychosocial adaptation to epilepsy: the role of coping strategies. Epilepsy \& Behavior 2001; 2 533-44.

[102] May T.W., Pfafflin M. The efficacy of an educational treatment program for patients with epilepsy (MOSES: results of a controlled, randomized study). Epilepsia 2002; 43 539-49. 
[103] Dilorio C., Shafer P.O., Letz R., Henry T.R., Schomer D.L., Yeager K. et al. Project EASE : a study to test a psychosocial model of epilepsy medication management. Epilepsy \& Behavior 2004; 5 926-36.

[104] Kobau R., Diloro C. Epilepsy self-management: a comparison of self-efficacy and outcome expectancy for medication adherence and lifestyle behaviours among people with epilepsy. Epilepsy \& Behavior 2004; 4 217-25.

[105] Kurtz L.F., Powell T.J. Three approaches to understanding groups. Social Work Groups 1987; 103 69-80.

[106] Trostle J.A., Hauser W.A., Sharbrough F.W. Psychological and social adjustment to epilepsy in Rochester, Minnesota. Neurology 1989; 36633.

[107] Baker G.A. People with epilepsy: what do they know and understand, and how does this contribute to their perceived level of stigma? Epilepsy \& Behavior 2002; 3 S26-32.

[108] Bishop M. Barriers to employment among people with epilepsy: Report of a focus group. Journal of Vocational Rehabilitation 2002; 17 281-286. 